\title{
On the Organization of Growth and Differentiation in the Stem of the Sunflower.
}

\author{
BY \\ D. THODAY, M.A., \\ Harry Bolus Professor of Botany in the University of Cape Town.
}

With Plate XVII and ten Figures in the Text.

THIS paper is the outcome of an inquiry into the meaning of the 1 irregularity of the zone of secondary wood in the old stem of Helianthus anmus, which in this respect stands in marked contrast to the stems of most woody plants. ${ }^{1}$

The stem of a young Sunflower plant has the usual ring of vascular bundles, bulging a little in comformity with the prominence of the leaf-bases, but otherwise regular (Text-fig. 2). The medullary rays are not very wide, so that the arrangement of the tissues is not conspicuously different from that in young twigs of a multifasciculate type of structure. It is during growth in thickness that the contrast develops.

In the secondary growth of most woody twigs, secondary tissue is added more or less regularly and uniformly by radial activity of the cambium. The primary xylem and the pith appear to

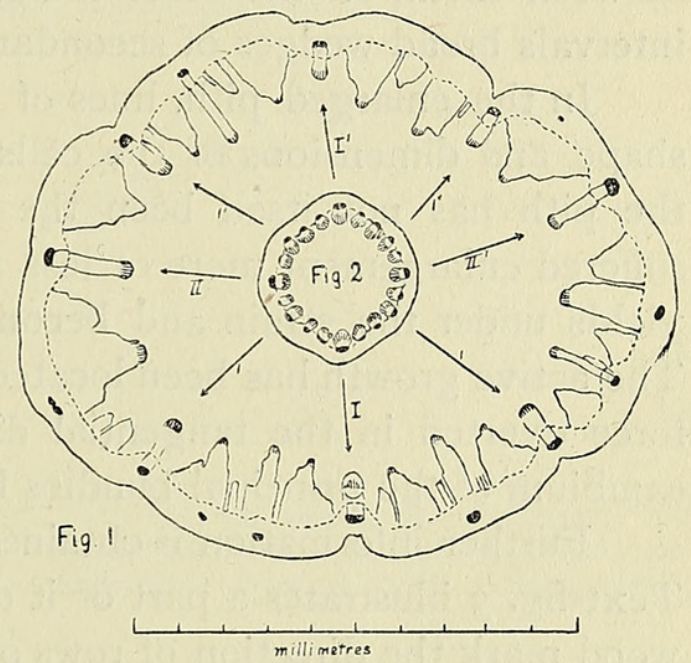

Text-FIG. I. Transverse section through the middle of the third internode of a stem over a centimetre in diameter, showing the irregular formation of secondary wood. $I, I^{\prime}$, median and $i, i, i^{\prime}, i^{\prime}$, lateral trace bundles of leaves at the node above; $I I, I I^{\prime}$, median trace bundles at the next (fourth) node. Fibres are shown black.

TEXT-FIG. 2. (Inset in Text-fig. I on same scale.) Same region of a young stem. remain unaffected by the mechanical disturbances that strain the outer tissues.

1 Compare Thoday, Botany, Cambridge Univ. Press, I919, Fig. 35, p. I 38.

Annals of Botany, Vol. XXXVI. No. CXLIV. October, 1922.] 
In the Sunflower stem, on the contrary, the pith increases greatly in diameter and the bundles become widely separated. Text-figs. I and 2 represent sections through the third internode above the cotyledons of two plants of different age. Both are drawn to the same scale and the insetting of Text-fig. 2 in Text-fig. I serves to emphasize the point in question. The diameter of the pith has increased approximately threefold during the growth that has occurred between the two stages represented. Both plants were grown in the same plot, and at the earlier stage the diameters of their stems were of the same order of magnitude.

In the older stage certain of the primary bundles are still readily distinguishable. Six of them $\left(I, i, i\right.$ and $\left.I^{\prime}, i^{\prime}, i^{\prime}\right)$, which belonged to the pair of leaves at the node next above, are conspicuous by reason of their small radial extent-the fascicular cambium has not been very active. Two other bundles ( $I I$ and $\left.I I^{\prime}\right)$ are the median bundles belonging to the pair of leaves at the second node above. In these the cambium has been more active radially. But all these eight bundles and a few others are alike in their small width, which is little if at all greater than the width of the original primary bundle (Text-fig. 2). The width of the intervals between them, on the other hand, has increased enormously, and in these intervals broad wedges of secondary wood have been formed.

In the enlarged pith, lines of strain are expressed in the arrangement, shape, and dimensions of the cells (Text-fig. 3), which clearly indicate that the pith has not itself been the active agent in the expansion, but has suffered enlargement more or less passively. Indeed, in still older stems it yields under the strain and becomes hollow (compare Plate XVII, Fig. 5). The active growth has been located in the cambial region and the expansive force exerted in the tangential direction. ${ }^{1}$ In this tangential growth the cambium of the principal bundles has taken little or no part.

Further information is obtained from a closer study of the older section. Text-fig. 3 illustrates a part of it on a larger scale. The radial lines in the wood mark the direction of rows of elements formed by individual cambium cells : their divergence in parts of the sectors between the principal bundles is clear evidence of tangential growth at these points (see also Plate XVII, Fig. 4). It is also evident, however, that the sectors have been augmented by the extension of cambial activity into the adjoining medullary rays, which have widened considerably to accommodate it. On either side of each of the principal bundles the rays have widened still further, and are now bridged by cambium. Here the cambium has not given rise to any secondary wood, and therefore is either recent or relatively

1 Cf. Sachs, Textbook, p. I25: 'This increase in diameter of stems which accompanies, or even for a short time outlasts, the growth in length, is frequently occasioned mainly by the tangential extension of the outer layers of tissue, while that of the pith does not keep pace with it. The pith will then split and the stem become hollow.' But Sachs appears to refer here rather to the cortical parenchyma. 
inactive. Evidences of strain in the inner part of the rays show that it is in the cambial region that the tangential growth has occurred.

Accommodation phenomena. A full understanding of the unequal distribution of tangential growth involves a knowledge of the course of the bundles and secondary wood-sectors in adjacent parts of the stem, for accommodation is of course mechanically necessary. The widening of the rays flanking the principal bundles is probably in part an accommodation phenomenon of this kind, correlated with the growth of wood-sectors above the outgrowing leaf-trace bundles.

Other examples are found at the base of the stem. For instance, the median paired bundles of the cotyledonary traces become widely separated

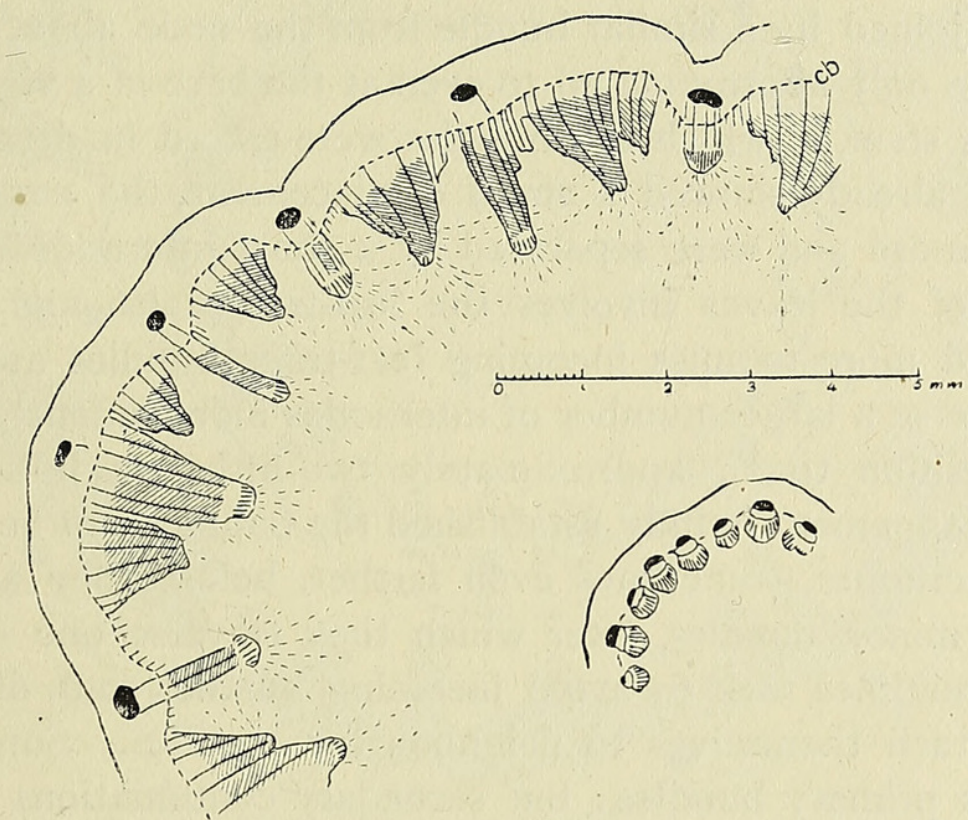

'Text-Fig. 3. Parts of Text-figs. I and 2 enlarged. The 'radial' lines in the wood show the direction of rows of elements formed by cambial cells. The broken lines in the pith represent lines of strain. Secondary wood shaded; rows of vessels indicated in primary xylem; fibres black; $c b$, cambium.

in conformity with the tangential growth of a massive wood-sector in the internode above. At a later stage the interval is bridged by secondary wood.

Another example is afforded by the diminution of tangential growth downwards in the lowest epicotylar internode and the hypocotyl. As the root is approached the pith suffers less and less enlargement and tapers to a point in the transition region. This is a natural accommodation to the absence of pith in the root. There is a complementary increase in radial activity of the cambium down to the root, where tangential growth would obviously be unsuitable to the mechanical requirements. It is largely for this reason that the base of the stem is so much more woody, compared with parts a little higher, than mere difference of age would lead one to 
expect. $^{1}$ There are, however, other correlations between hypocotyl and root which require further investigation.

Course of bundles. As the arrangement of the leaves is at first opposite and decussate, but later alternate, the course of the leaf-trace bundles shows a corresponding change. In a plant growing under favourable conditions the change of phyllotaxy begins after about four pairs of opposite leaves have appeared. The trace bundles of the third pair pass down through three internodes and then usually fork, but sometimes deviate without forking, so avoiding the incoming leaf-traces of the first pair. The median bundles of the first pair similarly fork past the lateral cotyledonary trace bundles. If the leaves at alternate nodes were exactly superposed, the bundles would typically pass through two internodes, then fork, each branch being joined by a similar bundle from the node above. This ideal arrangement is only approximated to even at the base of a vigorous plant. ${ }^{2}$ In a particular stem, in which the bundles were traced in detail, the fourth pair of leaves already showed a small displacement, the next two leaves deviated still more and were separated by a short internode. The lateral displacement of the leaves involves the leaf-traces also and the bundles tend more and more to miss incoming leaf-trace bundles at lower nodes and so to traverse a larger number of internodes independently.

The transition to an approximately two-fifths phyllotaxy is rapid. When this arrangement is fully established the bundles can be followed for about five internodes, sometimes even farther, before they are joined by one or more minor bundles, after which they traverse one or two more internodes, sometimes fork to avoid incoming bundles, and, diminishing in size, finally attach themselves to neighbouring bundles. Sometimes they end blindly as primary bundles; but secondary continuations link them to neighbouring strands.

There is nothing stereotyped about this disposition of the bundles. The facts can best be understood as a solution of the problem of accommodating the traces of an increasingly rapid succession of leaves. The space available diminishes downwards : firstly, by reason of the entrance of other traces at each node ; secondly, because towards the base of the plant all the primary tissues are on a smaller scale. Trace bundles from the upper leaves are therefore crowded into narrower spaces and ultimately unite with one another. It is these synthetic traces that grow tangentially and that form the massive wood-sectors so conspicuous at the base of the stem. They always communicate directly with the upper, still expanding part of the shoot. Moreover, their growth is correlated with that of the

1 It may be thought that these accommodations have been emphasized unduly, but Jeffrey and others who have started with a phylogenetic point of view seem to have entirely missed them. See below, pp. 5०3-5, for further discussion.

2 But a close approximation to it is found in starved dwarf plants, where it persists through several internodes. Cf. p. $5^{\circ} 2$. 
shoot as a whole in a way that stands in marked contrast to the behaviour of the local leaf-traces.

This contrast, which has been illustrated already for the base of the stem, is not peculiar to that region. Under sufficiently favourable conditions a considerable amount of secondary thickening may occur at higher

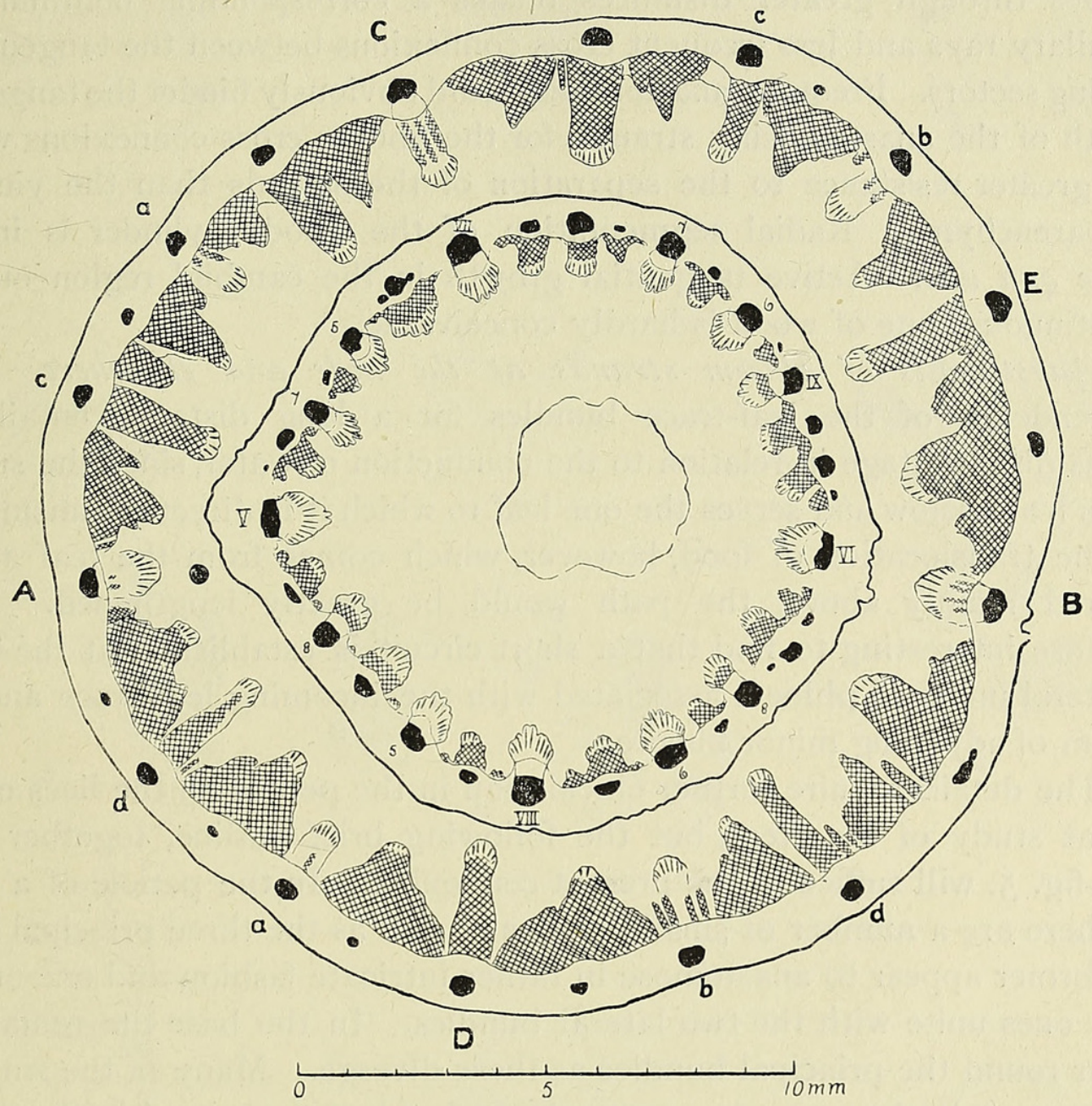

TEXT-FIG. 4. Sections in the region of transition to two-fifths phyllotaxy of two stems of different age drawn to the same scale. Fibrous secondary xylem cross-hatched; rows of vessels indicated in primary xylem; fibres black. Secondary growth, tangential in character, has occurred between the two stages represented. In the earlier stage tangential growth had already resulted in the collapse of the pith in the centre. A, B, C, D, median trace bundles belonging to leaves at successive nodes above the older section (see Text-fig. 9); $a, a$, \&c., corresponding lateral bundles. (Photographs of this section are reproduced in Plate XVII, Figs. 5 and 6.) In the younger section the chief bundles are numbered according to their node of exit-median trace bundles with roman, lateral with arabic numerals.

levels, and the farther it proceeds the more clearly is the same mode of organization revealed. Text-fig. 4 illustrates this. It represents a section of the stem of a tall plant, which already bore a giant capitulum, taken through the region of transition to two-fifths phyllotaxy; also inset and represented on the same scale for comparison is a section through the corresponding region of a younger plant. The secondary growth is of the same tangential character and is localized in the synthetic traces. Plate XVII, 
Figs. 5 and 6 , are photographs of the larger section; they show the hollowness of the pith and the lines of strain in the outer still intact part of it.

Incidentally the structure of the upper part of the stem is the better adapted to tangential growth, since the independence of the leaf-trace bundles through greater distances means a corresponding continuity of medullary rays and less frequent cross-connexions between the tangentially growing sectors. Frequent anastomosis would obviously hinder the tangential growth of the anastomosing strands, for the fibrous cross-connexions would offer greater resistance to the separation of the strands than the yielding ray parenchyma. Radial segmentation of the woody cylinder is indeed a sine qua non. Active tangential growth in the cambial region outside a continuous zone of wood is hardly conceivable.

Anastomosis of phloem strands at the node and elsewhere. The independence of the leaf-trace bundles for a long distance entails no serious disadvantage in relation to the conduction of water, since the supply comes from below and serves the one leaf to which it is directly transmitted. For the translocation of food, however, which comes from the leaf and is required mainly above, the path would be greatly lengthened. It is therefore interesting to find that a short circuit is established at the node, by lateral union of phloem associated with the incoming leaf-trace and the phloem of adjoining minor bundles.

The details require further elucidation in the petiole on the lines of the present study of the stem, but the following brief outline, together with Text-fig. 5, will suffice in the present connexion. In the petiole of a large leaf there are a number of small bundles as well as the three principal ones. The former appear to anastomose in rather intricate fashion and one or two larger ones unite with the two lateral bundles. In the base the remainder cluster round the principal bundles as these diverge. Many of the smallest consist, even in the case of a mature leaf, of phloem only, and in the others the xylem dies out in the nodal region. Thus, just above the level at which the trace bundle enters the vascular zone of the stem, there are associated with it a number of small strands of phloem, which encircle the xylem (Text-fig. 5 (6)).

At the same level cambium is continuous across the rays. In the case figured the two small bundles are the branches of a small bundle which has forked just above. At the approach of the leaf-trace bundle these branches diverge, the cambium ring bulges inwards and divides to admit the xylem of the incoming bundle. Meanwhile the phloem strands that encircle the latter take their place as they arrive, along with a few other phloem strands already present, outside the cambium, and follow it when it divides. The free ends of the divided ring then gradually withdraw into the undistorted parts adjoining, and the associated phloem strands crowd together, along 

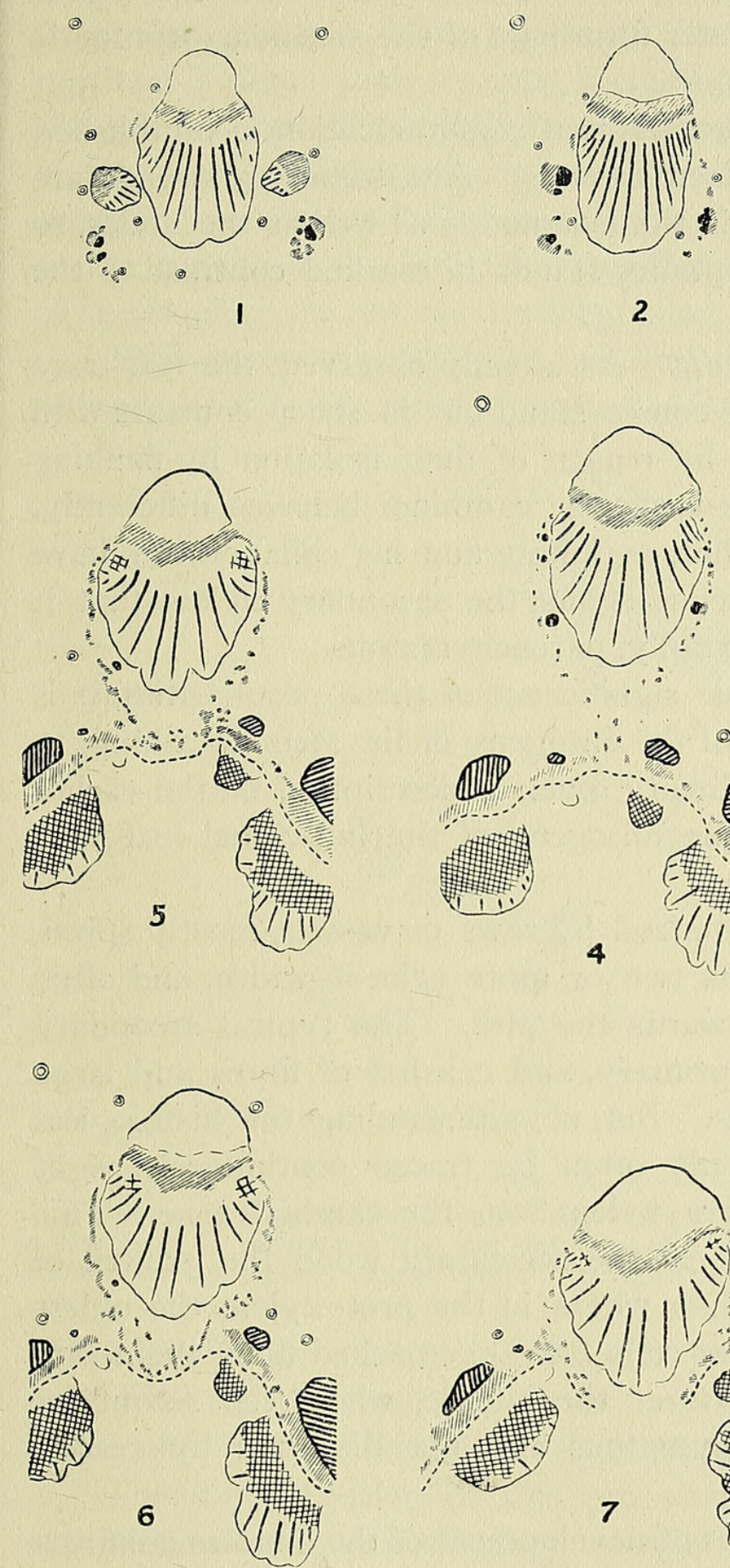

2

\section{(4)}

(c)
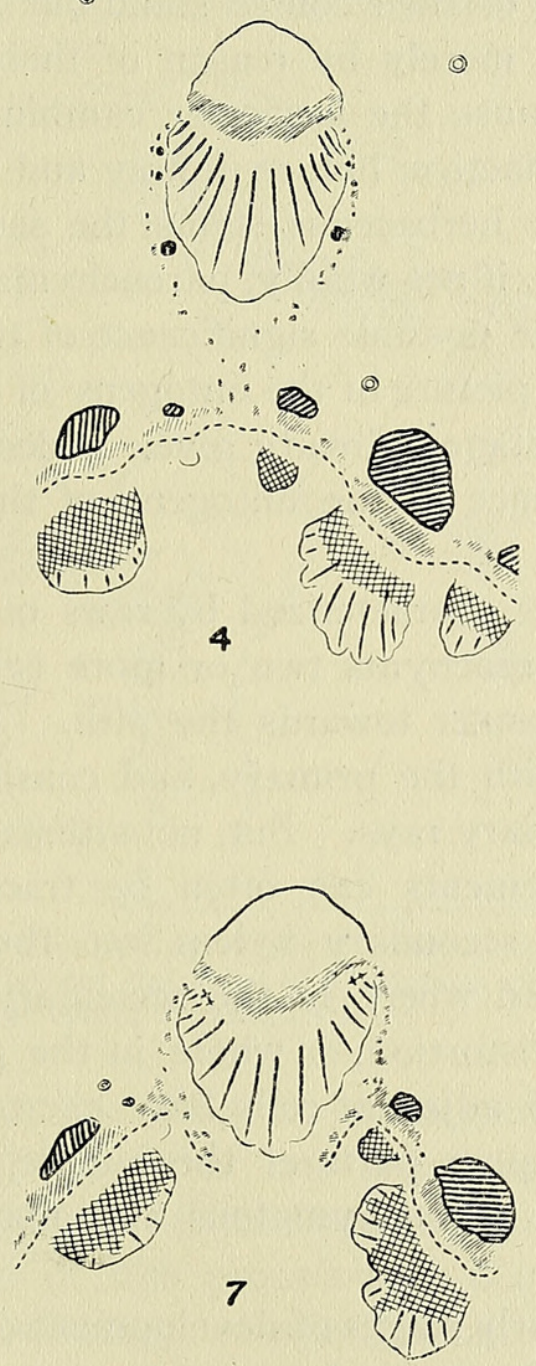

(1)

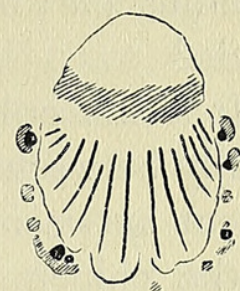

3

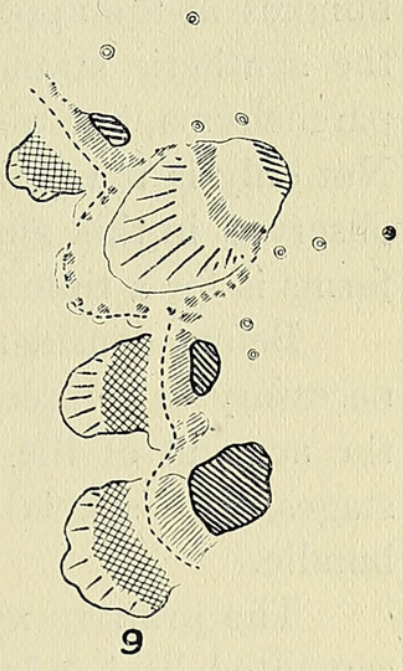

$\frac{10}{0.5}+\frac{1}{10} \mathrm{~mm}$

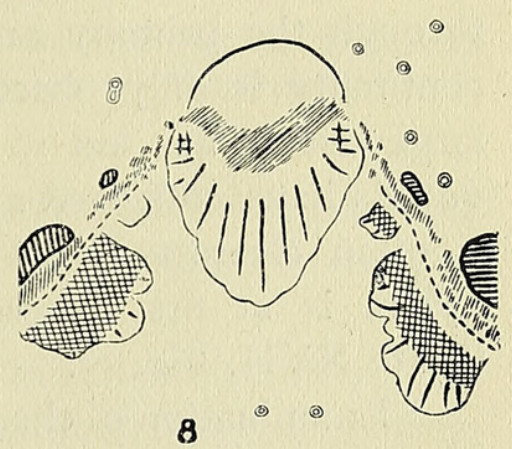

TEXT-FIG. 5. (I) to (8) Sect ons of a median leaf-trace bundle at right angles to its course from the leaf-base through the node, showing accompanying phloem strands, which form a plexus on each side in the node, connecting with the phloem of adjoining bundles. (9) A lateral trace bundle entering at the node showing similar features. Lignified fibres heavily shaded; phloem finely shaded; secondary wood cross-hatched; rows of vessels indicated in the primary xylem. Xylem of small satellites of the trace bundle black. (Resin canals omitted from (5) and (7).) 
with other incoming strands on both sides of the incoming bundle. Thus a phloem plexus is formed on each side, in close association with the phloem of the adjoining bundles which communicate with the upper expanding part of the shoot and later form part of the secondary synthetic strands. ${ }^{1}$

It is not only at the node, however, that communication is established laterally between the principal phloem strands. Anastomosing strands are frequent between all the bundles, in the internodes as well as the nodes, so that the phloem in its lateral continuity stands in marked contrast to the xylem.

Ontogeny of the leaf-trace bundle. As already observed, the leaf-trace bundles in the upper part of their course stand out in sharp contrast with the synthetic strands, not merely by reason of their isolation by flanking parenchyma, but also because the fascicular cambium behaves differently. Not only is it relatively inactive, but, as Jeffrey and his collaborators have observed in this and other herbaceous stems, the secondary xylem that it forms is for a time largely, if not wholly, parenchymatous.

Before considering the possible significance of these peculiarities, it is necessary to complete the picture of the ontogeny of the stem by adding to the account of the later stages already given a description of the earlier stages, with special reference to the ontogeny of the individual leaf-trace bundle.

The primary xylem is characterized by rows of vessels, mostly spiral, separated by bands of parenchyma two or more cells in width, and often diverging in a fan-like manner towards the pith. The typical secondary wood contrasts sharply with the primary, and consists of fibres and large pitted vessels, with medullary rays. But, notwithstanding the histological contrast, the rows of elements can often be traced continuously right through the primary and secondary xylem into the cambial zone. This continuity is only obscured where in the secondary wood the growth of large vessels has led to distortion, or where in the protoxylem the oldest vessels have collapsed and adjacent cells have encroached upon them. It is often clearest in the upper parts of the bundle, where the secondary xylem is at first largely parenchymatous and not distorted by vessels (Plate XVII, Fig. I).

Examination of the early stages of development of the bundles confirms the inference that the primary and secondary xylem are formed by the activity of the same cambium and are only distinguishable histologically.

If a vigorous plant is selected while it still shows no sign of the inflorescence, but is already producing a succession of large leaves, trans-

1 In the case figured the axillary growing-point was latent and no vascular supply to it was even foreshadowed. Where an axillary bud is developed its vascular cylinder opens inwards and joins the vascular zone of the stem above the median leaf-trace bundle. 
verse sections at short distances from the apex may legitimately be taken to represent, approximately, different stages of the ontogeny at one level in that region, for the size of the mature primary bundles of successive leaftraces has become fairly constant. Text-fig. 6 represents corresponding portions of three such sections, including the principal leaf-trace, drawn to the same scale. It exhibits in a striking manner the great increase in size of the bundles, their progressive separation with the growth of the whole stem, and the interpolation of additional bundles in the widening intervals. In the growth of the individual bundles it is to be observed that the rows of vessels increase not only in length but in number.

Still nearer the apex the bundles are represented by small groups of procambial cells separated by narrow radial bands of developing parenchyma.

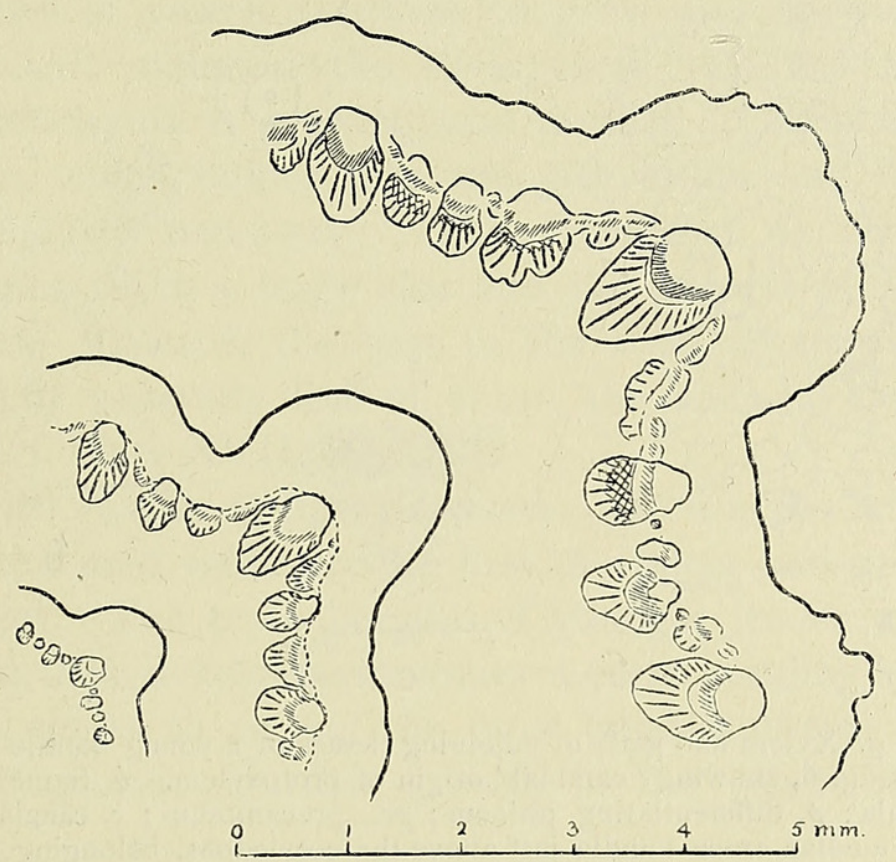

TEXT-FIG. 6. Corresponding portions of three sections, each including the three bundles of a leaf-trace, at different levels near the apex of a vigorous plant not yet beginning to flower. Phloem and procambium shaded except in earliest stage.

These groups increase in size and soon become distinguishable into an outer part, with the cell contents rather less dense, which ultimately forms the fibres, and an inner crescent of denser procambium.

The differentiation of this procambium does not correspond to the current view of the development of a collateral vascular bundle, according to which the procambial cells begin to differentiate on the outside as protophloem and on the inside as protoxylem. In this stem, cambial activity begins very early on the inner margin of the procambial crescent, and the whole of the xylem is the product of this. Moreover, the procambial crescent grows laterally, the cambium extending also along its inner margin.

In the earliest stage of the differentiation of vessels clearly recognizable 
in transverse section two cells are distinguishable by their larger size and less dense contents, one lying outside the other near the inner margin of the procambial crescent and in the median line. By the time the number of cells in the row has reached about four, the innermost has been differentiated as a vessel, and two other similar rows, each of two or three cells, are distinguishable on either side of the first row a little removed from it. Text-fig. $7, a$, represents a slightly later stage. The first vessel has been differentiated in each of the lateral rows and the third in the median row, where the two oldest already show signs of weakening. Laterally, still other rows have been initiated.

Between the rows of vessels the cells cut off by tangential divisions

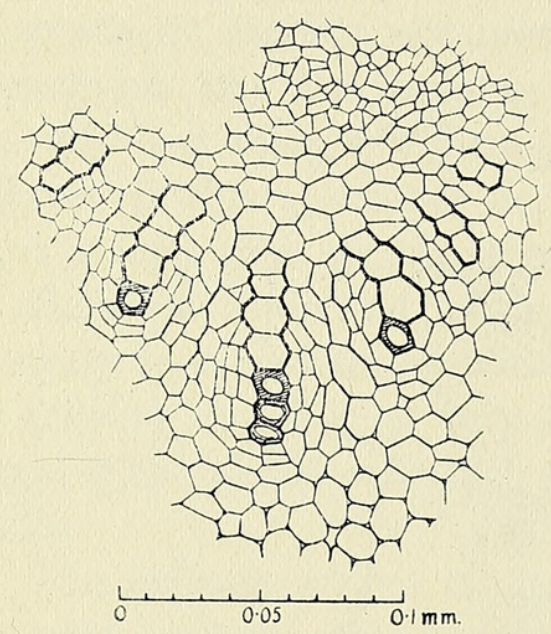

a

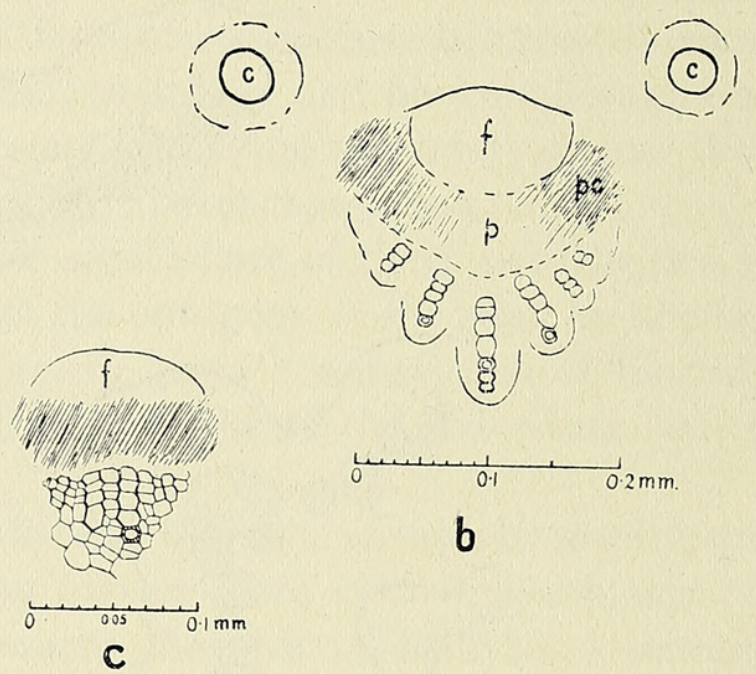

TEXT-FIG. 7. a. Xylem and parts of adjoining tissues of a young bundle near the apex of the same plant as Text-fig. 6, showing 'cambial' origin of protoxylem. $b$. Same bundle on a smaller scale: $f$, fibre initials; $p$, differentiating phloem; $p c$., procambium; $c$, canals associated with the bundle. $c$. Young median trace bundle just above the cotyledons, belonging to one of the leaves at the second epicotylar node of a young plant. Here also the protoxylem is 'cambial' in origin.

divide further by radial walls, particularly those in immediate proximity to the vessels, and thus form round the rows close sheaths of small cells with dense contents. Midway between the rows the cells divide less and their contents become less dense. In a mature bundle the sheaths are collenchymatous and conspicuously chlorophyllous, ${ }^{1}$ without air-spaces. For variable distances from the pith they are separated by narrow bands of larger cells with air-spaces but less chlorophyll.

At the stage corresponding to Text-fig. $7, a$, the differentiation of phloem was already proceeding in the median part of the procambial crescent, but the ends of the crescent were still in the procambial condition and actively growing (Text-fig. $7, b$ ): The crescent extends in this way at both ends and the differentiation of phloem follows in both directions from

1 Indeed, the vascular zone is the greenest part of the stem! 
the centre. Cambial activity also extends along the inner margin and additional rows of vessels appear.

At a later stage the cambium often adds also to the phloem, but it is difficult to tell how much of the phloem of a mature bundle has originated from it.

The characteristic fan-like divergence of the rows of vessels towards the pith is the resultant of several factors, and varies in degree. The cambium is more or less curved $a b$ initio, and the rows of elements tend to be at right angles to it. The curvature becomes more obvious as the cambium, following the procambial crescent, extends laterally. Later, the expansion of the fibres and the formation of additional phloem by the cambium diminish its curvature. On the other hand, the cells between the rows of vessels continue to grow and so widen the spaces between them and maintain the divergence. At the same time the surrounding parenchyma is growing, and mutual adjustment between this and the bundle, which bulges into the pith within and into the cortex without, is obviously necessary. The divergence is most pronounced where the bundles reach a large size and the general primary expansion is most vigorous. Towards the base of the stem, where the bundles are small and growth generally less vigorous, the rows of vessels are often nearly parallel (cf. Plate XVII, Fig. I).

The leaf-trace bundle at different levels. At a given level the bundles that belong to the next node are the first to appear and are precocious in their development. The trace bundles of younger leaves are successively interpolated and their development shows a corresponding lag. When the primary growth comes to an end the trace bundles of two or three leaves are already full grown. Further growth in the others is secondary in character.

The structure of different regions of an individual trace bundle of a fullgrown leaf varies accordingly. For two or three internodes (in the upper part of the stem) the xylem is more or less constant in form and size and consists entirely of primary tissue. Most of the vessels are spiral or annular, or partly annular and partly spiral. The last one or two in each row show reticulations or include an occasional pitted vessel. Farther down the amount of primary xylem diminishes and secondary xylem is associated with it in increasing amount (Text-fig. 8). It may be inferred that in the first two or three internodes the trace bundle reaches practically its full size while growth in length is still proceeding and the surrounding parenchyma is still growing actively; and further that in the uppermost internode it is not only precocious but reaches its full size before the primary growth of the rest of the tissues is complete.

So long as growth in length continues, vessels put out of action by elongation are doubtless replaced, and the last vessels are such as could be 
formed only when growth in length comes to an end. But even when these are pitted vessels they are smaller in diameter than the spiral vessels formed during the period of most active growth of the bundle, and far smaller than the pitted vessels typical of the secondary wood (see Text-figs. 8 and 9). The bundle may therefore be said to have a grand period of transverse growth which corresponds to that of the leaf to which it belongs but is more or less independent of that of the internode in which it occurs.

At the end of this period the cambium becomes sluggish and remains so for a considerable time. In the large bundles of the upper part of the stem the cambial zone often develops air-spaces and becomes parenchymatous, especially the median part, so that a definitive cambium cannot be located. This applies throughout the upper part of the bundle where its development is completed during the primary phase.

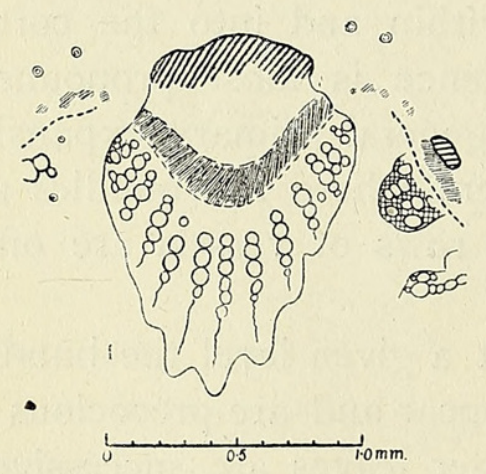

TEXT-FlG. 8. Sections of the median trace bundle of the leaf (already mature) at the seventh node of a vigorous plant: (I) in internode VII; (2) in internode V; (3) in internode IV. In the last, the small amount of primary xylem is supplemented by secondary xylem (cross-hatched) with large pitted vessels.

Farther down, where the primary growth of the parenchyma comes to an end while the leaf to which the bundle belongs is still expanding, the further growth of the bundle is affected and the additional xylem, although it is formed by the same cambium, develops the histological characters of secondary wood, with much larger pitted vessels, solid bands of fibres, and secondary medullary rays.

This formation of secondary xylem, once it has well begun, continues steadily and the cambium does not become dormant as in the internodes above. This is illustrated by Text-fig. 9, which represents bundles from one and the same section of an old stem. They are the median bundles belonging to leaves of successive nodes above the plane of section, and therefore of diminishing age; but the youngest, $\mathrm{D}$, has formed far more xylem than the others. Here, too, it includes large pitted vessels which have been produced in normal proportion along with the wood fibres throughout the period of growth. In bundle $\mathrm{C}$ the secondary xylem is 
less in amount and at first consisted mainly of fibres. Only later was the formation of vessels resumed, and these were small. Comparison with bundle $\mathrm{D}$, and with adjoining regions, where in the latest xylem the vessels diminish to a corresponding size, suggests that the plant is coming to the end of its growth (the inflorescence was already expanded), so that the cambium of bundle $\mathrm{C}$ never awakened to full secondary activity. In bundle $\mathrm{B}$ the cambium has been still less active; it formed at first only

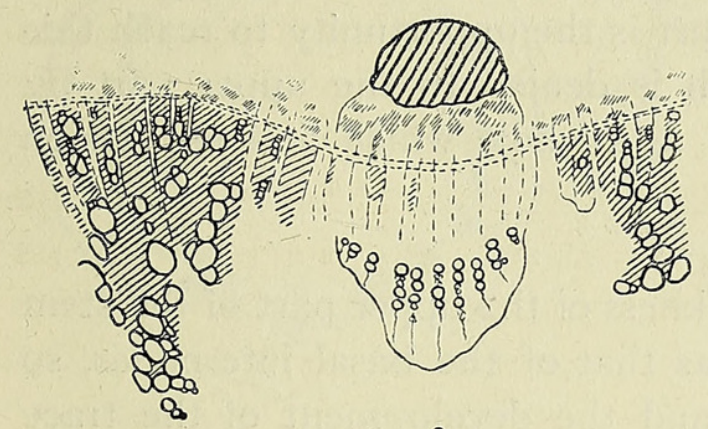

A

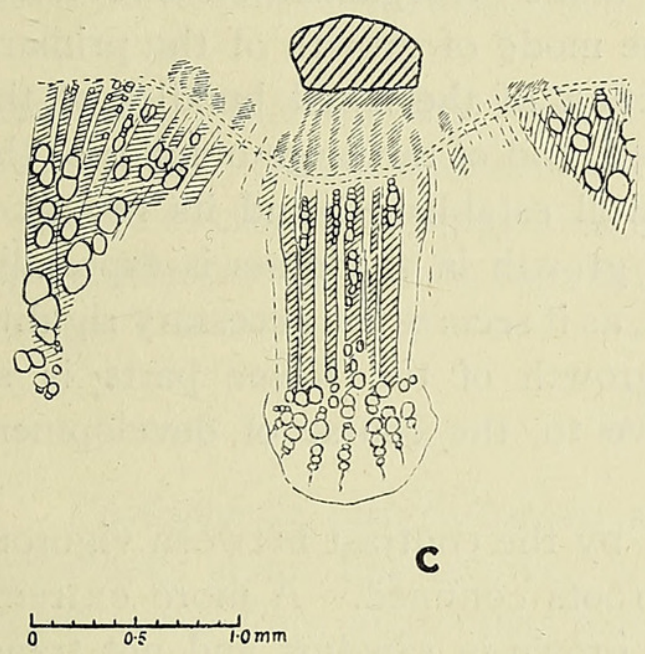

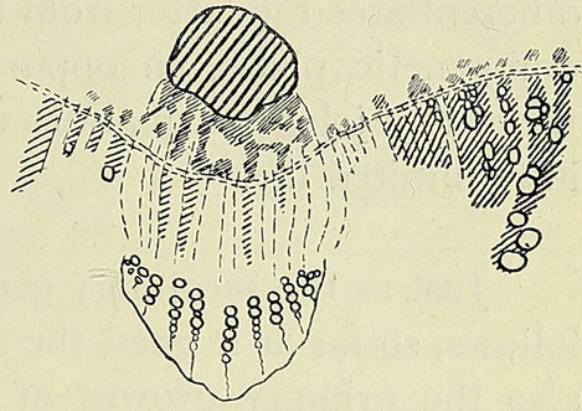

B

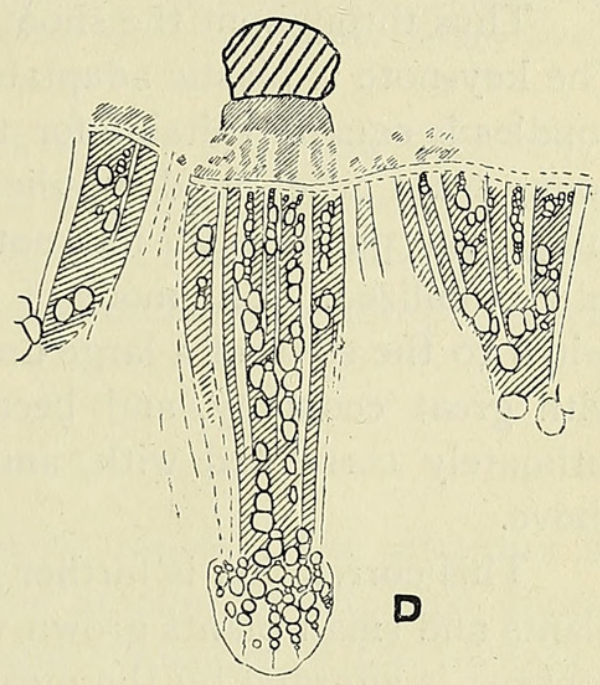

TEXT-FIG. 9. A-D. Median trace bundles at one level, belonging to leaves at four successive nodes above the plane of section, drawn from the section shown in Text-fig. 4 and Plate XVII, Fig. 5, illustrating the behaviour of the fascicular cambium at different distances from the leaves (see text). Wood fibres shaded.

parenchyma and then added a few bands of fibres but no vessels. In bundle A there is least secondary tissue and that is almost wholly parenchymatous.

Between corresponding parts of one leaf-trace bundle the contrast would be even greater.

Latest phase. In older, lower internodes later stages in the ontogenetic sequence are to be found, but on a smaller scale. Throughout the leaf-trace bundle the cambium ultimately awakens to full secondary activity and 
gives rise to typical secondary wood with vessels, fibres, and medullary rays. By this time the tangential growth has ceased, the primary medullary rays have been bridged by cambium, and a uniform zone of wood is formed by radial activity of the continuous cambium, as in a typical woody stem, until the growth of the plant as a whole comes to an end (Plate XVII, Fig. 3).

From a morphological point of view this final resemblance to a woody stem cannot be regarded as a peculiarity of the basal region. What differentiates the latter from the upper part is the opportunity to reach this ontogenetic phase, an opportunity which is denied to the upper part by those physiological qualities of the plant as a whole which find expression in its limited life.

Just as the secondary growth in thickness of the upper part of the stem follows, so far as it goes, the same lines as that of the basal internodes, so also the primary growth of the latter and the development of the trace bundles of the lowest leaves take place in the same way as has been described for the upper part of the shoot. ${ }^{1}$

Thus throughout the shoot the same mode of organization is revealed. The key-note is plastic adaptability. The mode of growth of the primary bundles is equally suitable for the production of the small bundles of the young plant, when food supplies are limited, and of the large bundles of the full-grown plant, with its root system well established and its resources fully mobilized. The mode of secondary growth in thickness is especially suited to the stem of a large annual plant, as it secures the necessary rigidity with great economy, and because the growth of the lower parts is so intimately correlated with, and responsive to, the course of development above.

This correlation is further illustrated by the contrast between vigorous plants and small plants grown with their roots confined. A more extreme contrast is afforded by the meagre plants grown in sawdust and not transplanted. The mature plants are little more than a foot high, bear small few-rayed capitula, and have stems which even in the lower internodes are hardly thicker than those of the young plant. As Text-fig. Io illustrates, there is little secondary growth even in the lowest internodes; additional rigidity is secured by the lignification of the perimedullary parenchyma. It is also of some interest that the decussate arrangement of the leaves persists till just below the inflorescence, five or six pairs being formed.

This example shows the effect of mere starvation on the structure of a species which under favourable conditions shows a considerable amount of

1 The only apparent exception is the growth of the cotyledonary traces; but Chauveaud's seedling studies (Ann. Sci. Nat., Bot., $9^{\mathrm{e}}$ sér., xiii, I $9 \mathrm{I} I$, and other papers quoted therein) suggest that 'xylem superpose' is cambial in origin. Cf. also Lenoir, ibid., I92 I. 
secondary growth and produces a woody base closely resembling the stem of a woody plant. The approximation of the structure of the starved plant to that of an extreme annual is suggestive. With it may be compared Sinnott and Bailey's generalization " that an herbaceous stem, in all its
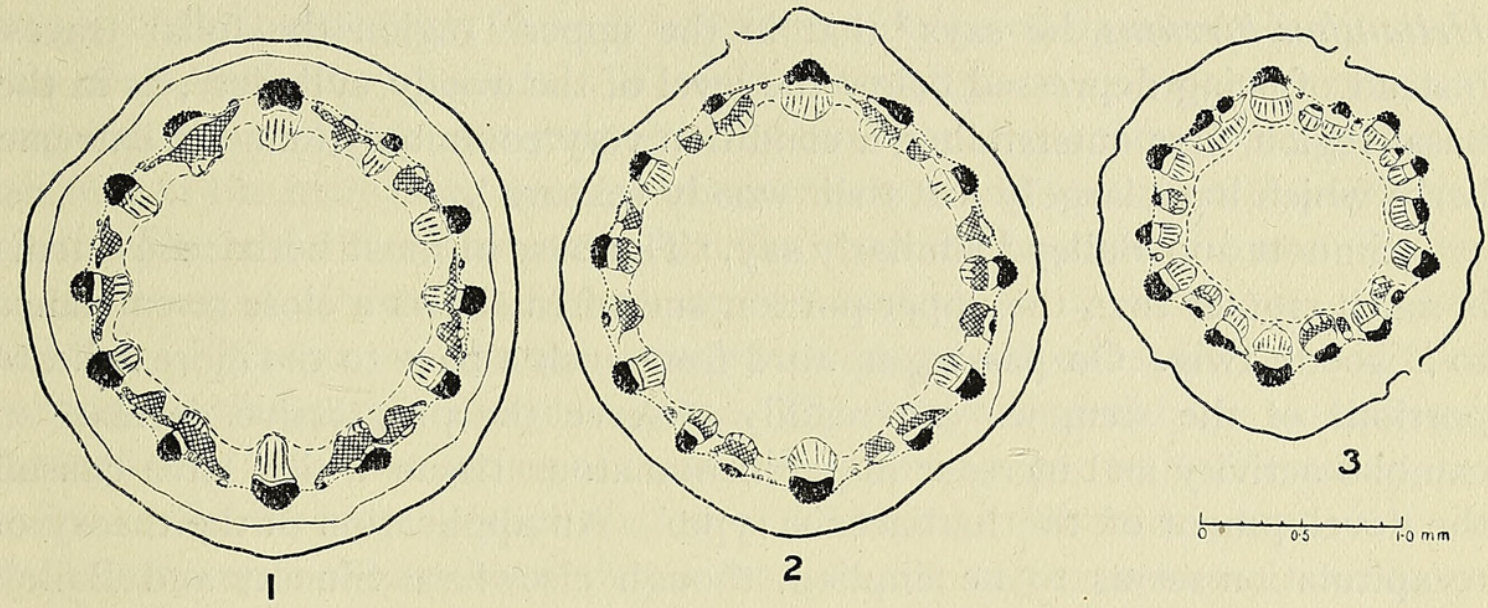

Text-FIG. Io. Sections of the stem of a starved dwarf plant already flowering. (I) First epicotylar internode (contrast Fig. 4, Plate XVII). (2) Third internode (cf. Text-figs. I and 2). (3) Sixth internode, near the capitulum. Endodermis dotted; the broken line indicates the boundary of the perimedullary lignified parenchyma; secondary wood cross-hatched (mainly fibres).

essentials, is like the first annual ring of its woody relatives'. It is not inconceivable that a shortening of ontogeny might gradually result from a change of climate or migration to a less favourable habitat through physiological effects analogous to starvation without any fundamental morphological change.

\section{Discussion.}

Phylogenetic interpretations and ontogenetic stages. The structure of herbaceous stems has received a considerable amount of attention within recent years from anatomists who have sought evidences of the evolution of herbaceous from woody types and have endeavoured to interpret this evolution as a progressive adaptation to a shortened life-cycle.

One class of anatomical evidence adduced is that derived from a comparison of upper and lower regions of the same stem, on the assumption that the base retains ancestral features. Such a comparison does not by itself provide adequate data regarding the ontogeny of a stem, for each region has its own ontogeny. The method adopted in the present study of the Sunflower, of comparing the same region of the stem in similar individuals of different age, provides the means of testing, in a particular example, the validity of evidence of the kind referred to.

Jeffrey has emphasized the differences between the upper and lower

1 Origin and Dispersal of Herbaceous Angiosperms. Ann. Bot., xxviii, p. 559, I9I4. 
regions of herbaceous stems and has applied the doctrine of recapitulation. For instance, ${ }^{1}$ he points to the 'circular and complete woody cylinder' in the lower region of the epicotyl and the multifasciculate structure of the upper region of the same plant as 'developmental evidence' pointing to the 'derivation of herbaceous forms from woody ones'. Again, referring to Helianthus hirsutus, he says ${ }^{2}$ that in the upper 'region the foliar traces, instead of being depressed below the level of the woody cylinder', as in the basal region, 'are outstanding, a condition very commonly found in extreme herbs which have largely lost their woody texture'.

Sinnott and Bailey ${ }^{3}$ similarly say, 'The base of most herbaceous stems is much stouter than the upper portion and often shows a close resemblance to a woody twig. On passing upward from such a base to the more delicate portions of the stem we can readily observe the progressive decrease in cambial activity and increase in parenchymatous tissue which have caused the development of the herbaceous type.' An application of the theory of recapitulation seems to be implied, though elsewhere Sinnott and Bailey show that they regard the theory as only to be applied with caution.

The points emphasized in the quotations are: (I) the woodiness of the base and the decrease in cambial activity upwards ; (2) the depression of the leaf-trace bundles in the lower region and their outstanding position in the upper region; (3) the increasing proportion of parenchymatous tissue upwards.

With regard to (2), Text-fig. 2 shows that in the lower internodes of Helianthus annuns, as well as in the upper, the median leaf-trace bundles are at first outstanding, in conformity with the decurrent leaf bases. This is the case even in the first epicotylar internode. They become depressed owing to the vigorous secondary growth of the segments on either side and the sluggishness of their own cambium. The more conspicuous prominence of the trace bundles in the upper part is an expression of their precocity and more vigorous growth. Even here their prominence diminishes as the stem grows in diameter, and, when secondary growth proceeds far enough, they become depressed as at the base of the stem.

Concerning (I), the greater woodiness of the base, it is obvious that as the lowest internodes are the oldest they have had most time in which to produce secondary wood. In the case of $H$. anmuns a comparison of the ontogeny of the upper and lower internodes reveals no fundamental difference in mode of organization. There is merely a change of scale, reflecting the increasing vigour of primary growth, ${ }^{4}$ and naturally in successively younger internodes less and less secondary wood. Secondary growth, so far as it goes, always follows the same course and shows the same distribution. At the

1 Anatomy of Woody Plants, Chicago, I917, p. 191.

2 Ibid., p. 403.

3 Origin and Dispersal of Herbaceous Angiosperms. Ann. Bot., xxviii, p. 559, I9I4.

4 In starved dwarf plants this increase of scale does not occur. See Text-fig. Io (3). 
very base the somewhat greater thickness of secondary wood than corresponds to mere age can be interpreted as an accommodation phenomenon appropriate to the transition from the tangentially expanding stem to the pithless, radially thickening root.

As regards (3), if upper and lower regions are compared at corresponding stages of their ontogeny, there is no clear evidence of an increasing proportion of parenchyma upwards. Moreover, in any given region, after primary expansion is complete, the proportion of functional parenchyma diminishes because of the increasing amount of secondary wood and the collapse of the pith. The real differences, therefore, between the upper and lower regions of the stem of Helianthus annuns are reduced to $(\alpha)$ a difference of scale and $(b) a^{\circ}$ difference of age and ontogenetic stage. Neither of these differences is fundamentally morphological. The morphological basis is the same throughout. Nor does either of these differences appear to justify an application of the theory of recapitulation. All that can be said is that, just as the Sunflower is shorter lived than a tree, so the upper part of a Sunflower is shorter lived than the base. All that remains as anatomical evidence for the derivation of this herbaceous stem from a woody form is simply the presence of a cambium which gives rise to woody tissues similar to those which characterize woody stems.

The increase of scale in the upper part of the shoot calls for some further consideration. Closely correlated with it is the secondary growth in thickness of the parts below by a method which allows of a rapid increase in diameter and at the same time is economical. Thus the necessary increase in rigidity keeps pace with the expansion above without drawing as heavily on the available food supplies as if the same increase in strength were secured entirely by radial growth, like that of a woody twig. A larger proportion of the food is therefore available for the young developing organs. The increasingly vigorous primary growth of these, which is reflected in the increase of scale, must involve a great expenditure of food material. Translocation must be proportionately efficient. Since Sachs's experiments Helianthus annuus has been well known as a plant which both assimilates and translocates the products of assimilation with remarkable rapidity. Recently Willstätter and Stoll ${ }^{1}$ have demonstrated that this species, along with certain other vigorous herbaceous plants, owes its capacity for rapid assimilation, not to a greater content of chlorophyll, but to greater efficiency of the chloroplasts themselves. It may be suggested that for the maintenance of this efficiency translocation must be correspondingly efficient so that accumulation of products is avoided. ${ }^{2}$

1 Untersuchungen über die Assimilation der Kohlensäure, Berlin, 1918, p. 85, \&c.

${ }^{2}$ Further light may be expected on this point from Briggs, Kidd, and West's quantitative studies of growth in Helianthus; cf., for instance, their reference to the possibility that the utilization of assimilable material, governed by temperature, might control assimilation. Annals of Applied Biology, vii, 1920, p. 217 . 
It has been shown how at the node and elsewhere there is anastomosis of phloem, independently of the xylem, so that a minimum path to the shoot apex is secured for at any rate a part of the products entering at the node. Whether in this respect the Sunflower is exceptional or whether by any other structural features translocation is specially facilitated are questions requiring comparative investigation. ${ }^{1}$

Whatever the answers to these questions may be, the fact remains that the rapid expansion of the shoot necessarily implies the rapid translocation of increasing supplies of food materials from the assimilating leaves. While expenditure of food increases with increase in the available supply, there seems no reason to expect increased storage. The emphasis laid by Jeffrey and by Sinnott and Bailey on the greater provision of storage tissue in herbs appears, therefore, to be exaggerated.

Direct evidence on this question is incomplete, but it may be noted that although starch appears in abundance in the leaf of the Sunflower as a transitory reserve, it is absent from the stem, except in the endodermis, and little inulin crystallizes out in alcohol.

It is also to be remembered that storage is not the only function proper to parenchyma, but that it plays a very important part in the mechanics of primary growth, especially in elongation.

Secondary parenchyma. Jeffrey has laid special stress on the parenchymatization of the sccondary xylem of the foliar traces as providing additional storage tissue. Here again there is no direct evidence that this secondary parenchyma is in the Sunflower specially concerned with storage. In any case there are other points of view from which it may have significance.

In the first place the secondary tissue in the leaf-trace bundle not only becomes more parenchymatous upwards, but.also diminishes in amount till at the node it is negligible. The mechanical aspect of this gradation is probably of considerable importance. If the cambium were radially active immediately below the node the primary xylem in the stem would be separated from the leaf base, and in the outgoing portion the vessels would be put out of action. Instead of this, the strain is evenly distributed and the primary xylem strand slopes gently outwards towards the point of departure from the vascular zone. The strain is not, however, wholly removed. Occasionally the secondary parenchyma just outside the primary xylem is stretched, like the pith within, and the primary xylem is isolated from the later fibrous secondary xylem. In such case the presence of yielding parenchyma is clearly of mechanical advantage, as well as the collenchy-

1 It is, of course, unlikely that the vigour of assimilation and growth depend wholly on structural features; e.g. Molisch (Mikrochemie der Pflanzen, I92I, p. 9I) names the genus Helianthus among 'nitrate plants', and with this and other herbaceous genera named as rich in nitrates contrasts trees as generally poor in nitrates. 
matous sheaths that surround the vessels and hold the primary xylem together. Ultimate partial or complete failure of accommodation to mechanical strains may account for the fact that the lower leaves wilt more readily, although they are nearer the water-supply, and finally shrivel. ${ }^{1}$

Correlations and their causal interpretation. Secondly, the variations in degree of activity of the cambium in the leaf-trace bundle and elsewhere demand, and should ultimately be susceptible of, a causal explanation. A brief consideration of the observed correlations from this point of view may perhaps be not unprofitable.

The sluggishness of the cambium in the upper part of the leaf-trace bundles is sufficient evidence that the greater cambial activity elsewhere is not determined by an abundance of food.

The sectors which show vigorous tangential growth are synthetic traces always in communication with young expanding leaves near the apex. There is a close correlation between the growth of these sectors and the expansion of the shoot as a whole.

The growth of the independent leaf-trace bundle is, on the other hand, closely correlated with the expansion of the leaf it serves, and tends to cease when the leaf has reached its full size:

In the lower part of the bundle, however, where primary growth comes to an end before the leaf is fully expanded, the primary xylem is supplemented by secondary xylem. It is an interesting fact that this secondary growth does not cease when the growth of the leaf comes to an end, but continues until the flowering season brings a diminution in the rate of growth of the stem as a whole. Thus, although at its initiation this secondary growth is correlated with the growth of the leaf, after initiation it ceases to show the same correlation, but is correlated instead with the growth of the plant as a whole.

The upper parts of the bundle reach their full size before primary growth has ceased around them. Secondary growth is then only slowly resumed, and the tissues produced reflect qualitatively as well as quantitatively the relative inactivity of the cambium, which is the more pronounced the nearer the node. From this point of view the so-called 'parenchymatization' of the xylem may mean simply arrested differentiation.

In the final stage of the resumption of activity, the cambium throughout the bundle produces typical secondary wood and behaves uniformly with the rest of the cambium at the same level, in correlation with the upper part of the shoot. This stage, however, is only represented in the older part of the stem, and is probably reached only when the leaves have fallen.

These correlations strongly suggest that each leaf has a sphere of influence in the vascular zone which is localized tangentially and longi-

1 Cf. Thoday, Proc. Roy. Soc., B., lxxxii, 1909, p. 25. 
tudinally. ${ }^{1}$ So long as a leaf is growing, its influence is felt throughout the bundles of its leaf-trace and the synthetic traces with which these are continuous below. The synthetic traces come under the combined influence of a continual succession of expanding leaves. The upper part of a leaf-trace, on the other hand, follows the lead of its own leaf, and its growth practically ceases when the leaf is fully expanded. The lower part commences to form secondary xylem under the influence of its own leaf, but this change from primary to secondary growth apparently involves a transference from the sphere of influence of the leaf into that of the apex. After the growth of the leaf has ceased the influence of the apex gradually encroaches still farther upwards until it controls the activity of the cambium throughout the bundle.

It seems necessary also to suppose that the sphere of influence of the leaf extends to the adjoining parenchyma of the medullary rays that flank the trace bundles and inhibits meristematic activity there; for otherwise it. is difficult to understand the fact that, in spite of the active extension of the cambium from the synthetic trace on the other side of a ray, the complete bridging of the ray by cambium, and still more by secondary wood, is so long delayed. This assumption gives a more precise meaning to the localization of the leaf-trace bundles in this multifasciculate stem, and also covers the persistence of the primary medullary rays which is a necessary condition of its specialized tangential mode of growth in thickness.

The view of the observed correlations here tentatively outlined is at least a useful working hypothesis. It suggests a field for experimental investigation in the study of the effects of removing leaves, at various stages of their development, on the growth of the trace bundles at different levels.

In conclusion, it may be pointed out that plants were intentionally selected for their freedon from lateral branches, which would have added further complications. A study of the way in which branches are accommodated and their influence on the main stem in this plant would not be without interest.

The only other species which has been examined for comparison is Helianthus tuberosus. The aerial stem of this species shows similar tangential growth, similarly distributed.

As regards the cambial origin of the primary xylem, this is probably a widespread phenomenon among Angiosperms. The absence of a sharp line of demarcation between primary and secondary wood has often been remarked upon. A casual glance at the first annual ring of the Oak and

1 If the correlations on which Miss Saunders has based her 'Leaf-skin Theory' (Ann. Bot., xxxvi, p. 135, 1922) are to be similarly interpreted, they imply a delimitation of spheres of influence in the superficial tissues on a plan very different from that which governs their delimitation in the vascular zone. 
other woody plants is sufficient to make the cambial origin of the whole of the xylem in them also highly probable.

Mrs. Arber's studies of Monocotyledons, ${ }^{1}$ on the one hand, and Chauveaud and, more recently, Lenoir's investigations of seedling ontogeny ${ }^{2}$ on the other, point largely in the same direction. But on this question more definite data are desirable.

\section{SUMMARY.}

I. The primary and secondary growth and differentiation of the stem of Helianthus annuus are described. The principal method employed was to compare the dimensions and structure of corresponding regions of different age and size.

2. In the primary differentiation of the leaf-trace bundle the small procambial strand is early distinguishable into an outer group of fibre initials and an inner procambial crescent which grows laterally. The whole of the xylem originates from a cambium which arises very near the inner margin of the crescent and extends tangentially in both directions pari passu with it. The bulk of the procambial crescent differentiates as phloem, beginning in the median region while the flanks are still meristematic and growing actively.

3. The primary growth of the stem is illustrated, including the interpolation of new bundles in the widening intervals between the precocious primary bundles. The transverse growth of a leaf-trace bundle is correlated with that of the leaf and not with that of the internode as a whole.

4. At the node the entering leaf-trace bundles are accompanied by strands of phloem which connect laterally with the phloem of adjoining bundles. Anastomosis of phloem strands is also frequent elsewhere.

5. Secondary growth in thickness is at first due to the activity of the cambium in the 'synthetic traces' that communicate directly with the upper still expanding leaves. This activity is in parts tangential as well as radial. Extensions of the cambium are also formed in the adjoining medullary rays, which widen to accommodate them. As a result of this tangential growth in the cambial region the pith is distended and often becomes hollow.

6. The cambium in the upper part of the mature leaf-trace bundles is meanwhile inactive and only gradually resumes active growth. The secondary xylem is at first largely parenchymatous. Towards the base of the stem a later stage of ontogeny is reached in which the fascicular cambium forms secondary wood in no way differing from that formed elsewhere.

7. The mode of growth, both primary and secondary, is the same from the basal internode throughout the stem. The differences are due to the larger scale of the primary tissues in the upper part and to the fact that the

1 Ann. Bot., xxxvi, p. 25 I, 1922, and other papers there cited.

2 Loc. cit. 
upper region represents an earlier phase of ontogeny than the woody base. The validity of Jeffrey's application of the theory of recapitulation to such differences is questioned.

8. The stems of small starved plants form very little secondary tissue even at the base, and their structure suggests comparison with smaller and shorter-lived annuals.

9. Various interpretations of the facts are discussed.

\section{EXPLANATION OF PLATE XVII.}

Illustrating Professor Thoday's paper on the Stem of the Sunflower.

The figures are reproduced from photographs of transverse sections.

Fig. I. One of the two principal median leaf-trace bundles at the middle of the first epicotylar internode of a young plant, showing the continuity of the rows of elements of the primary xylem through the cambial zone.

Figs. $2 a-2 f$. Sections of an old stem photographed about natural size in oblique illumination, with a dark background to show up the wood.

$a$, hypocotyl, about $\mathbf{I} \cdot 5 \mathrm{cms}$. below the cotyledonary node.

$b-e$, first epicotylar internode: $b$, just above the cotyledonary node; $c, \mathbf{I} \mathrm{cm} ., d, 2 \mathrm{~cm} ., e, 8 \mathrm{~cm}$. above the node.

The series $a-e$ illustrates the increasing distension of pith and diminishing thickness of the woody zone upwards (see p. 49I).

$f$, at a higher level, in the region of transition to two-fifths phyllotaxy.

Fig. 3. Same as $2 b, \times 4$. Base of first epicotylar internode, showing continuous zone of wood. The older wood, next the pith, is not continuous, and this together with the distension of the pith is evidence of an earlier tangential phase of growth. This has now been superseded by the later phase in which fascicular and interfascicular cambium behave uniformly and growth is radial, as in a woody twig.

Fig. 4. Same as $2 e, \times 4$. Upper part of same internode. Tangential growth is about at an end. The principal bundles are separated by broad wedges of secondary wood in which the divergence of the secondary medullary rays is evidence of tangential growth. The distended pith shows clear signs of strain.

Fig. 5. Same as $2 f, \times 4$. The number of bundles is larger, but tangential growth is still exhibited between the principal ones. The pith has given way in the middle and the outer intact zone shows evidence of strain.

Fig. 6. A part of the same section more highly magnified. The two bundles near the ends of the photograph are the median and one of the lateral trace bundles belonging to the leaf at the second node above the section. They show the parenchymatous nature of the secondary xylem formed at first by the cambium in the upper part of the leaf-trace bundles. 
Annals of Botany.
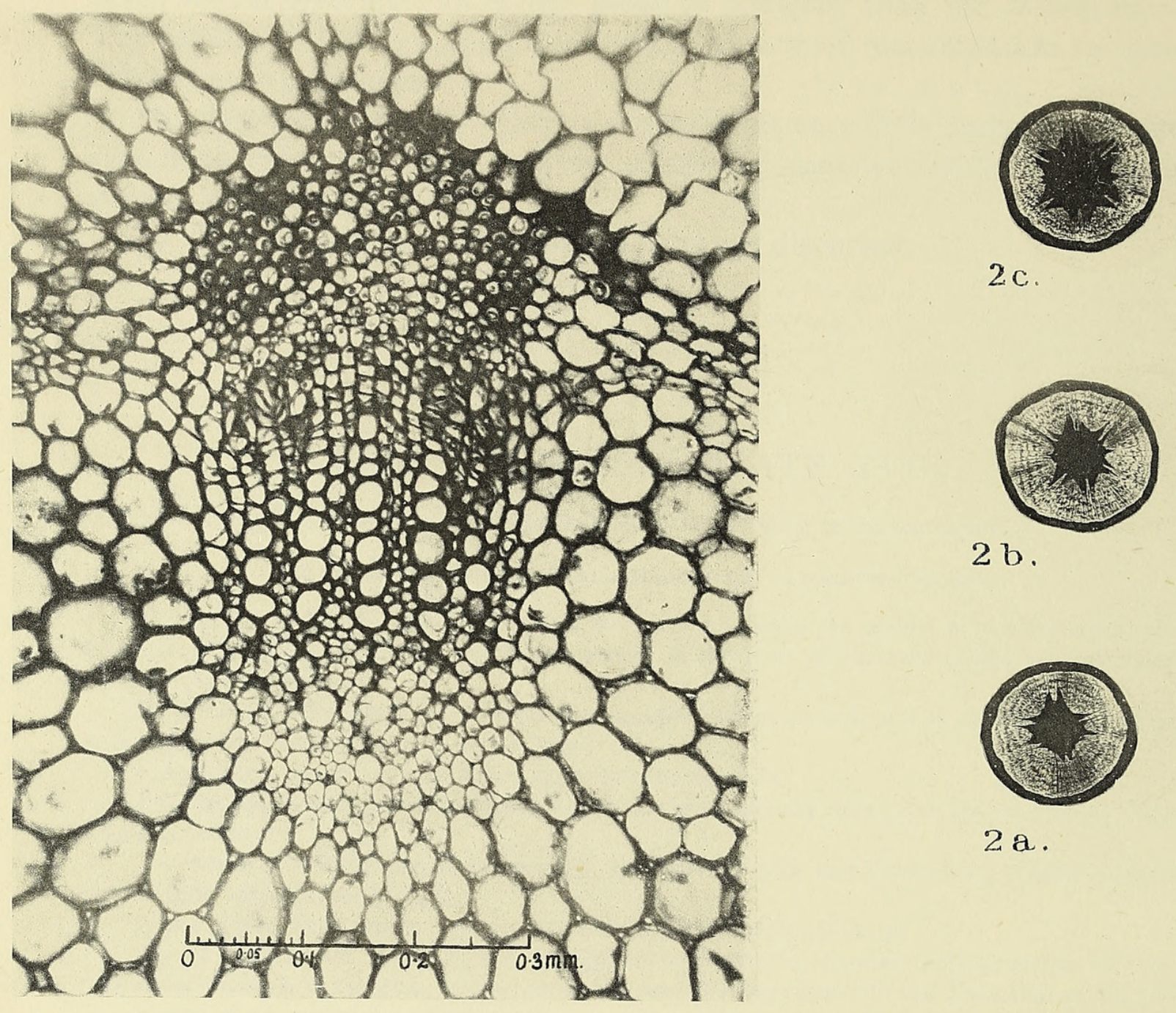

$2 \mathrm{c}$.

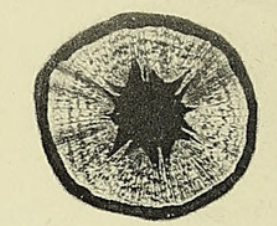

$2 \mathrm{~b}$.

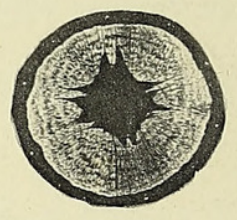

2 a.

1.

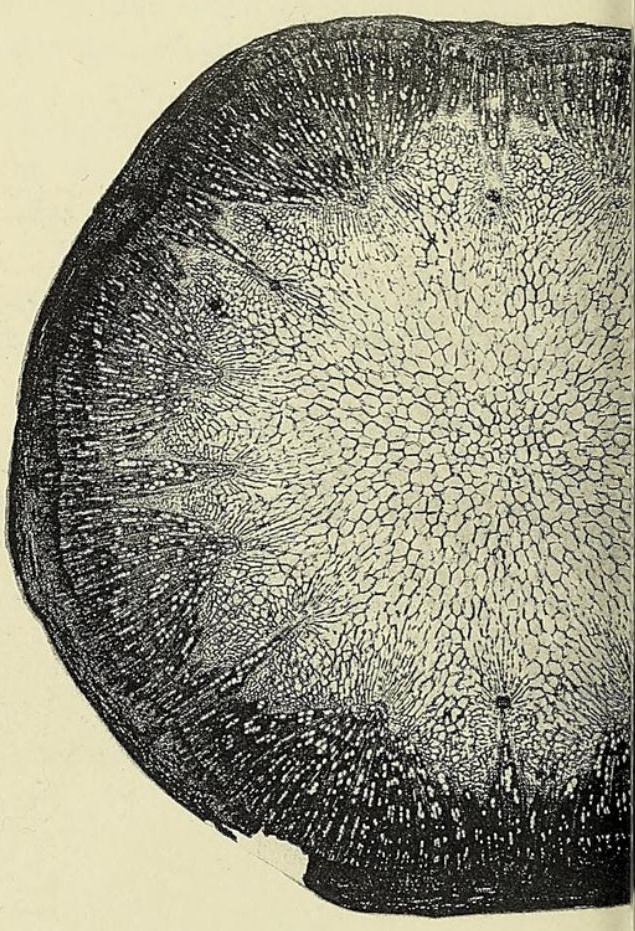

3.

THODAY-STEM OF SUNFLOWER. 
Vol.XXXVI, Pl. XVII.
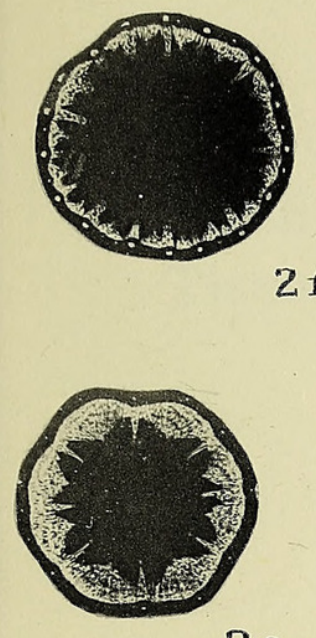

$2 \mathrm{e}$.

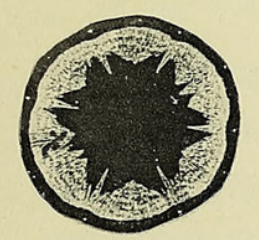

$2 d$.

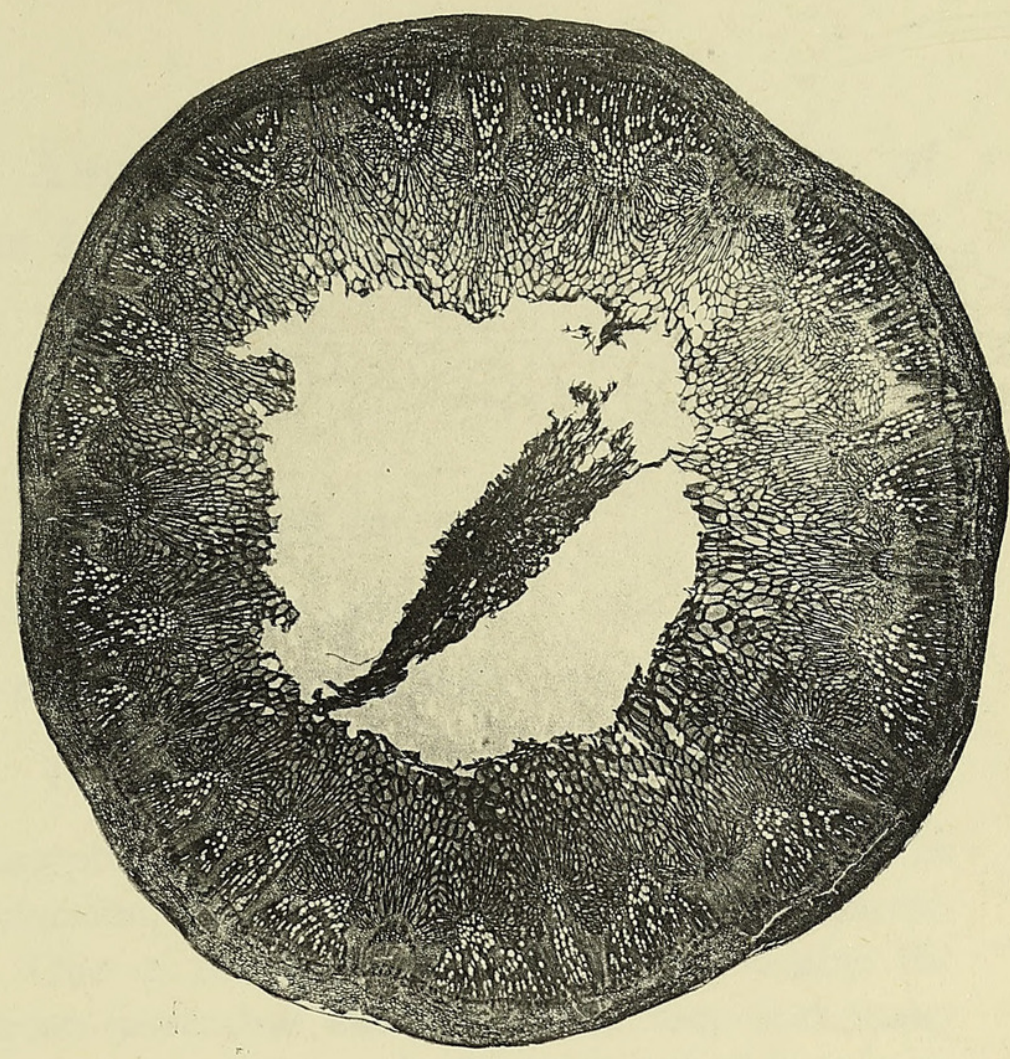

5.

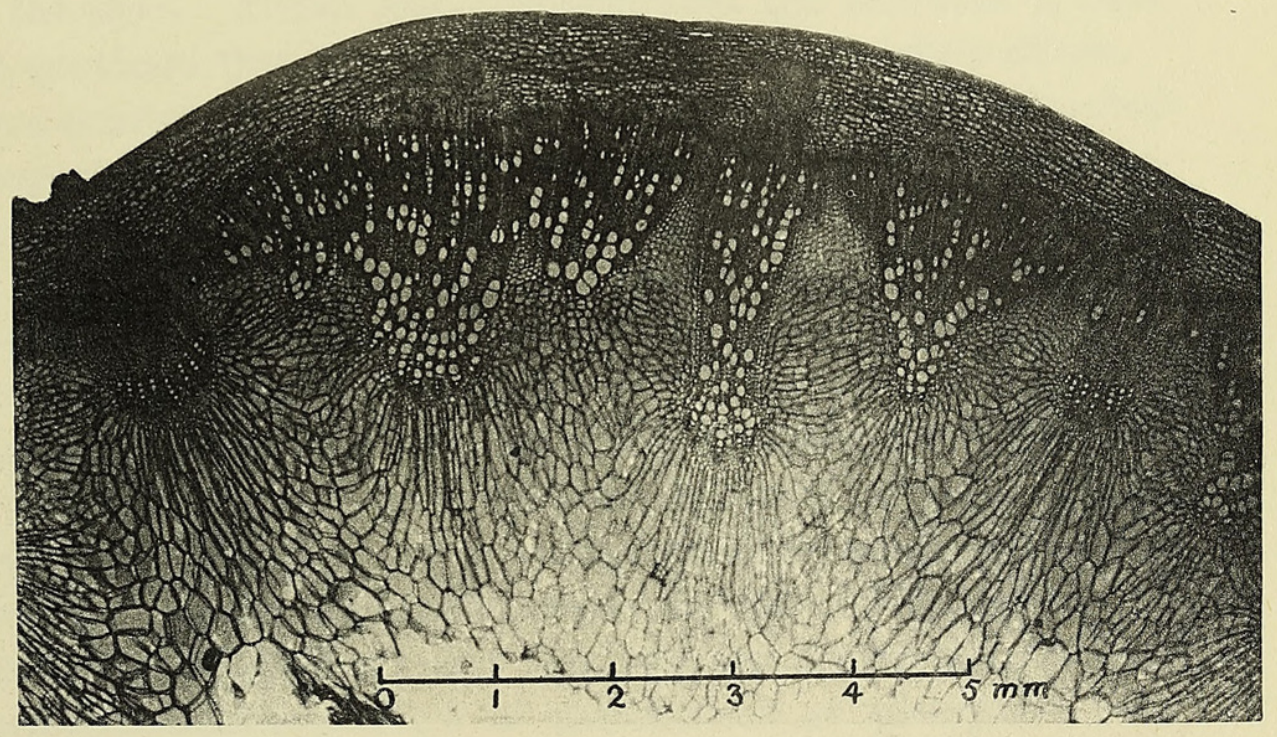

6.

4. 

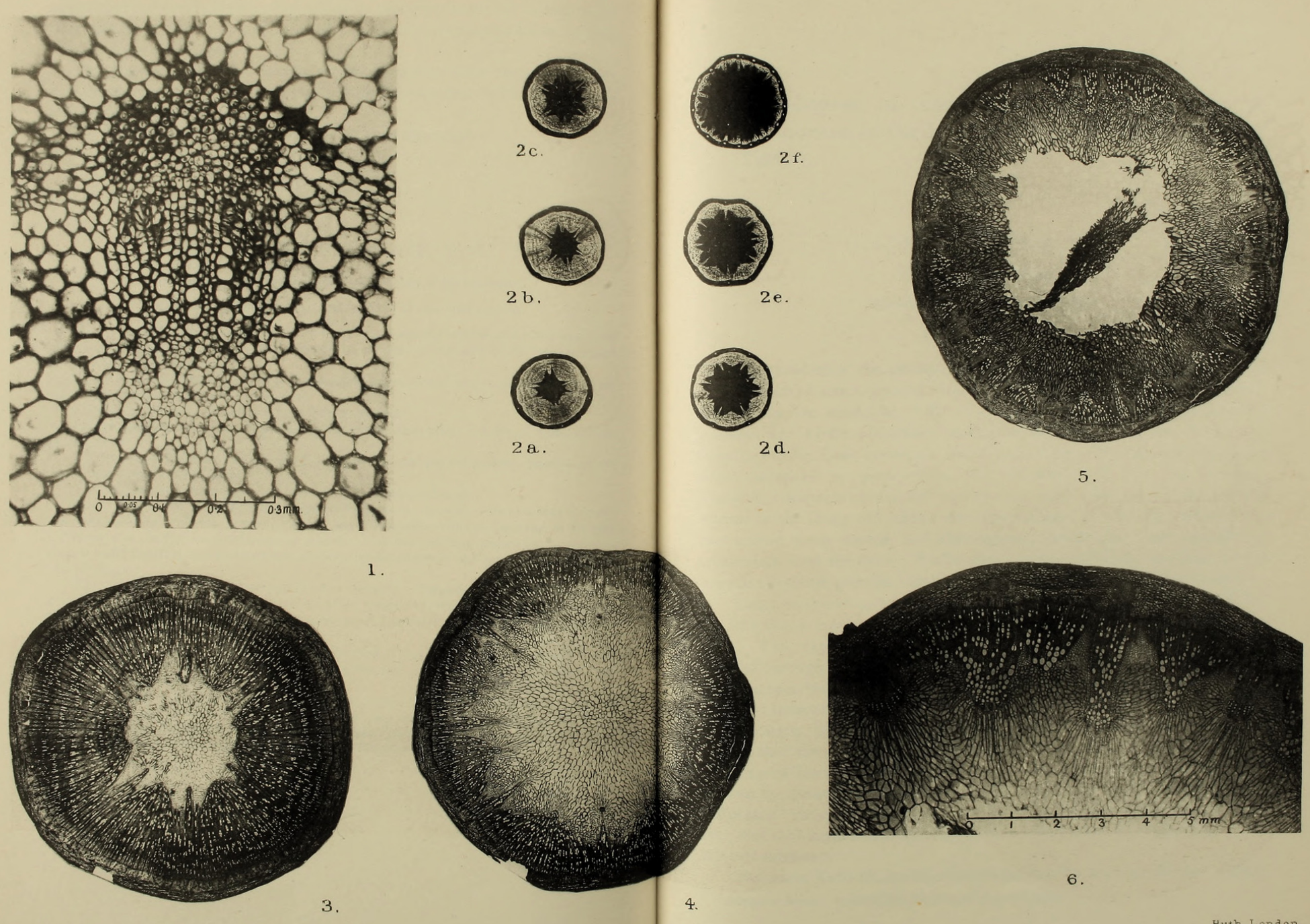

THODAY-STEM OF SUNFLOWER. 


\section{$2 \mathrm{BHL}$ Biodiversity Heritage Library}

Thoday, David. 1922. "On the organization of growth and differentiation in the stem of the sunflower." Annals of botany 36, 489-510. https://doi.org/10.1093/oxfordjournals.aob.a089819.

View This Item Online: https://www.biodiversitylibrary.org/item/234428

DOI: https://doi.org/10.1093/oxfordjournals.aob.a089819

Permalink: https://www.biodiversitylibrary.org/partpdf/319056

\section{Holding Institution}

Smithsonian Libraries

\section{Sponsored by}

Biodiversity Heritage Library

\section{Copyright \& Reuse}

Copyright Status: Not in copyright. The BHL knows of no copyright restrictions on this item.

This document was created from content at the Biodiversity Heritage Library, the world's largest open access digital library for biodiversity literature and archives. Visit BHL at https://www.biodiversitylibrary.org. 